\title{
Water Pollution and Health Impact in China: A Mini Review
}

\author{
Wen-Qing Lu*, Shao-Hua Xie, Wen-Shan Zhou, Shao-Hui Zhang, Ai-Lin Liu \\ Department of Occupational and Environmental Health, MOE Key Lab of Environment and Health, School of Public \\ Health, Tongji Medical College, Huazhong University of Science and Technology, Wuhan, Hubei, China
}

\begin{abstract}
For the last 20-odd years in China, an economic boom has resulted in severe environmental pollution; water pollution, particularly, is of great concern. It has been reported that pollution in China's overall surface water is rated medium. The water quality of groundwater, lakes and reservoirs has deteriorated. Consequently, such a general distribution of water pollution has posed a grave threat to public health in China. The health impact of water pollution has been documented in the last several decades; these documents are reviewed in this paper on several outstanding aspects, including chronic mercurialism, arsenism, cancers related to microcystins, health problems caused by organic pollutants and water pollution accidents as well. Indubitably, water pollution and its health impact remain enormous challenges in China.
\end{abstract}

Keywords: Water pollution, health impact, public health.

In the last 20-odd years, there has been a boom in economic development in China. However, a side effect that has resulted in is the increased severity of environmental pollution. Water pollution, especially, poses a grave threat to public health. The security of drinking water is not satisfactory. In order to promote public health, the government as well as the public, have paid greater attention to the cleanliness of water sources and the quality of drinking water.

\section{CURRENT SITUATION OF WATER POLLUTION IN CHINA}

\section{Shortage of Water Resources}

The total volume of fresh water in China reaches 2700 billion $\mathrm{m}^{3}$, which ranks sixth in the world. However, due to the huge population, the amount of water resources per capita is small: about $2200 \mathrm{~m}^{3}$, only equivalent to one fourth of the world average. This categorizes China as one of the thirteen countries with the lowest per capita water resources in the world [1]. Furthermore, the water resources distribution is uneven. The water resources per capita in northern China are especially poor; it only amounts to one fifth of southern China's and one tenth of the world average.

Water pollution is another trait of water resources in China. Water contamination, resulting from large amounts of untreated wastewater discharge, has caused ecological deterioration, declining the efficiency of water sources and reducing the quantity of water for use. With the influx of environmental pollution, the percentage of polluted water in urban areas is higher than $90 \%$. It is very difficult to find qualified water source locations in many cities. In the Pearl River and Yangtzi River Delta Areas, there is already water shortage despite the abundance of water due to water pollution [2]. The water resources shortage per se and pollution-

*Address correspondence to these authors at the Department of Occupational and Environmental Health, MOE Key Lab of Environment and Health, School of Public Health, Tongji Medical College, Huazhong University of Science and Technology, Wuhan, Hubei, China; E-mail: luwq@mails.tjmu.edu.cn induced water shortage have been the two biggest factors restricting sustainable development in China.

\section{Water Pollution}

\section{a. Water Quality of Rivers}

According to "Environmental Quality Standards for Surface Water" of China (GB3838-2002), the water bodies are divided into five grades based on utilization purposes and protection objectives. The contamination is aggravated in the order Grade $\mathrm{I}<$ Grade II $<$ Grade III $<$ Grade IV $<$ Grade V. The quality of drinking water supply sources should meet Grade II or Grade III surface water standards. "Report on the State of the Environment in China 2006" [3] reported that the pollution in China's overall surface water is rated medium. In 2006, the water quality of seven major rivers: the Yangtze River, Yellow River, Pearl River, Songhua River, Huaihe River, Haihe River and Liaohe River was basically similar to that of 2005. In the 408 key observation sections in 197 rivers of the seven main water systems monitored by the National Environmental Monitoring Center (NEMC), the percentages of water quality corresponding to inferior to Grade V, Grade V-IV and Grade I-III were $26 \%, 28 \%$ and $46 \%$, respectively. However, in $1996,51.1 \%$ of the rivers met Grade I-III, which shows a aggravated trend in water quality of China' s surface water during the past ten years [4]. In 2006, the water quality in the Pearl River and Yangtze River was satisfactory, while pollution in the Songhua River, Yellow River as well as Huaihe River was rated medium. The Liaohe River and Haihe River were heavily-polluted (Fig. 1). The Ministry of Water Resources of the People's Republic of China systematically investigated the nine main water resources for major pollutants in 2005 . The results are shown in Table 1 [5].

\section{b. Water Quality of Lakes and Reservoirs}

In 2006, the surface water quality of 27 major lakes and reservoirs were monitored by the State Environmental Protection Administration of China. These met Grade II, Grade III, Grade IV and Grade V surface water quality, respectively accounting for $7 \%, 22 \%, 4 \%$ and $19 \%$. About $48 \%$ of these 


\section{口Gradel-III $\square$ GradelVV $\square$ inferior to Grade V}

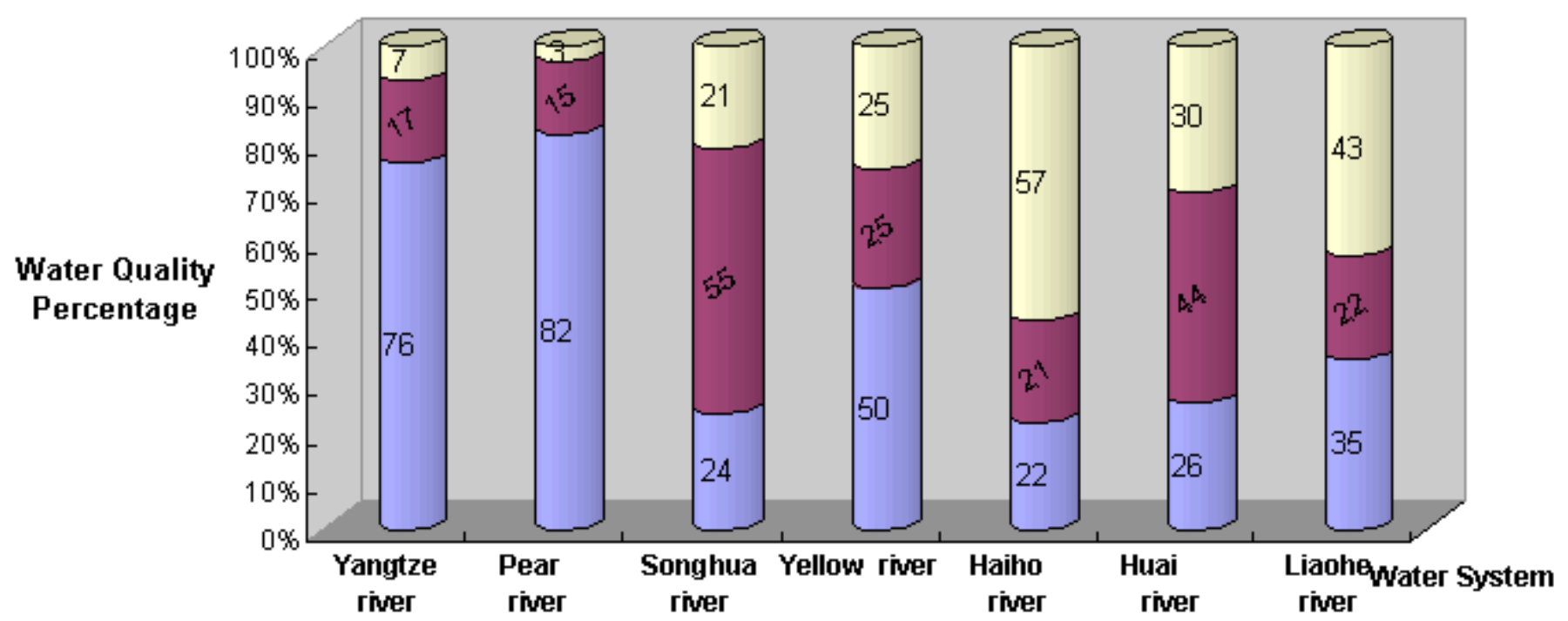

Fig. (1). Comparison of water quality in the seven major rivers in 2006.

Table 1. Major Pollutants Beyond the Standard in the Mainstream of the Nine Main Water Resources

\begin{tabular}{|c|c|c|}
\hline Songhua River Basin & 13443.9 & $\mathrm{COD}$, ammonia nitrogen, permanganate index and $\mathrm{BOD}_{5}$ \\
\hline Haihe River Basin & 11808.1 & $\begin{array}{l}\text { ammonia nitrogen, } \mathrm{COD} \text {, permanganate index, } \mathrm{BOD}_{5}, \mathrm{DO} \text {, volatile } \\
\text { phenol and TP; the level of fluoride, } \mathrm{Cd}, \mathrm{Hg} \text { and lead is above the } \\
\text { standard in part of some rivers }\end{array}$ \\
\hline Yellow River Basin & 13228.4 & $\begin{array}{l}\mathrm{COD} \text {, ammonia nitrogen, permanganate index, } \mathrm{BOD}_{5} \text {, volatile } \\
\text { phenol etc. }\end{array}$ \\
\hline Huai River Basin & 13856.4 & permanganate index, ammonia nitrogen, $\mathrm{COD}$ and $\mathrm{TP}$ \\
\hline Yangtze River Baisn & 38306.0 & $\begin{array}{l}\text { permanganate index, ammonia nitrogen, } \mathrm{COD}, \mathrm{BOD}_{5}, \mathrm{TP} \text {, oils and } \\
\text { fecal coliforms etc. }\end{array}$ \\
\hline Rivers in Northwest China & 9927.8 & COD, TP, ammonia nitrogen, permanganate index and fluoride \\
\hline
\end{tabular}

COD: chemical oxygen demand; $\mathrm{BOD}_{5}$ : five day biochemical oxygen demand; DO: dissolved oxygen; TP: total phosphorus.

lakes and reservoirs fell inferior to Grade V. $8 \%$ of the 25 lakes and reservoirs suffered from serious eutrophication. Mild and moderate degrees of eutrophication existed, respectively, in $32 \%$ of the lakes and $2 \%$ of the reservoirs. Among the "Three Key Lakes" (Taihu, Chaohu and Dianchi) that had been under special management and control, Chaohu Lake only met Grade V water quality standard, while Taihu and Dianchi Lakes fell inferior to Grade V. Chaohu and Taihu Lakes were under moderate eutrophication and Dianchi Lake was in hyper eutrophic state. Major pollutant parameters and the water quality of the "Three Key Lakes" as well as of the 10 major reservoirs are listed in Tables $\mathbf{2}$ and $\mathbf{3}$ [3].

\section{c. Groundwater Quality}

It is estimated that in China, the supply of drinking water for $70 \%$ of the total population and more than $95 \%$ of the rural population comes from groundwater [6]. More than 400 cities use groundwater; in fact in some cities, groundwater becomes an exclusive water supply source [7]. The water quality of shallow and deep groundwater showed an aggravated trend in 21 of 125 cities. This pattern also occurred in 12 of 75 cities involved in the 2006 monitoring [3].

\section{d. The Major Pollutants}

Industrial effluence and domestic sewage were the two principal causes of water pollution in China. The Ministry of 
Table 2. Major Pollutant Parameters and the Water Quality of the Three Lakes in 2006

\begin{tabular}{|l|c|c|c|c|c|c|}
\hline Name of Lake & Grade of Water Quality & Nutrition Level & Permanganate Index (mg/L) & TP (mg/L) & TN (mg/L) & $\begin{array}{c}\text { Chlorophyll } \\
\text { (mg/L) }\end{array}$ \\
\hline \hline Tai Lake & Inferior to Grade V & Moderate eutrophication & 4.6 & 0.08 & 3.17 & 0.05 \\
\hline Chao Lake & Grade V & Moderate eutrophication & 5.8 & 0.15 & 1.61 & 0.023 \\
\hline Dianchi Lake & Inferior to Grade V & Heavy eutrophication & 7.1 & 0.95 & 9.15 & 0.09 \\
\hline
\end{tabular}

TP: total phosphorus; TN: total nitrogen.

Grade V: applicable to the water bodies for agricultural use and landscape requirement.

Table 3. Water Quality of 10 Major Freshwater Reservoirs in 2006

\begin{tabular}{|l|c|c|c|c|c|}
\hline \multirow{2}{*}{ Name of Lake or Reservoir } & \multirow{2}{*}{ Index of Nutrition State } & Nutrition Level & \multicolumn{2}{|c|}{ Grade of Water Quality } \\
\cline { 3 - 6 } & & & $\mathbf{2 0 0 6}$ & $\mathbf{2 0 0 5}$ \\
\hline \hline Danjiangkou Reservoir & 32 & Mesotrophic state & III & III & ND \\
\hline Dahuofang Reservoir & 61 & Moderate eutrophication state & Inferior to Grade V & Inferior to Grade V & TN \\
\hline Yuqiao Reservoir & 47 & Mesotrophic state & V & IV & TN \\
\hline Songhua Lake & 47 & Mesotrophic state & V & TN \\
\hline Miyun Reservoirs & 54 & Mild eutrophication & III & III & ND \\
\hline Dongpu Reservoir & 44 & Mesotrophic state & III & III & ND \\
\hline Laoshan Reservoir & 44 & Mesotrophic state & Inferior to Grade V & Inferior to Grade V & TN \\
\hline Menlou Reservoir & 44 & Mesotrophic state & Inferior to Grade V & Inferior to Grade V & TN \\
\hline Qiandao Lake & 30 & Oligotrophic state & III & III & ND \\
\hline Shimen Reservoir & ND & ND & II & II & ND \\
\hline
\end{tabular}

TN: total nitrogen.

Index of nutrition state: calculated by formulas in which chlorophyll, total phosphorus, total nitrogen, SD transparency and $\mathrm{COD}_{\mathrm{Mn}}$ are all considered. The nutrition state is classified using the numbers $0-100$. The larger the number is, the severer nutrition state is:

Grade I: applicable to the water from sources and the national nature reserves; Grade II: applicable to first class of protected areas for centralized sources of drinking water; Grade III: applicable to second class of protected areas for centralized sources of drinking water; Grade IV: applicable to the water areas for industrial use and entertainment which is not directly touched by human bodies. Grade V: applicable to the water bodies for agricultural use and landscape requirement.

ND: no data.

Water Resources disclosed that the total quantity of wastewater discharge across the country in 2006 amounted to 73.1 billion tons, of which $2 / 3$ was from industrial sectors and $1 / 3$ was from tertiary industry as well as urban domestic sewage [8].

The major pollutants in industrial wastewater and domestic sewage include heavy metals $(\mathrm{Hg}, \mathrm{Cd}, \mathrm{Cr}, \mathrm{Pb}, \mathrm{Zn}$, etc), non-heavy metals (As, CN, F, S, Se, etc), organs (alkanes, substituted benzenes, PAHs, phthalate acid esters, etc), inorganic compound (P) and microorganisms (enteric pathogenic bacterium, virus, parasites, etc). In addition, chlorination of drinking water is the principal method used in China to ensure the safety of drinking water. As the water source in China is generally polluted by organic compounds, a large quantity of byproducts is produced from the chlorination disinfection process. Strong mutagens, such as MX, have been detected in the drinking water of some cities in China [9]. These byproducts in China's running water supply networks are clearly health hazards; they have attracted more and more attention from the scholars as well as the government.

\section{HEALTH IMPACT OF WATER POLLUTION IN CHINA}

According to figures from the Ministry of Health and the Ministry of Water Resources in 2004, at least 300 million people in China did not have access to piped water [10]. As a result of inadequate drinking water quality, the population still suffers from a considerable number of water-related diseases. The effects of water pollution in China on public health have been documented in the last several decades. In the following examples, these effects are especially evident:

\section{Chronic Mercurialism}

Reports of chronic poisoning caused by water pollution are actually rare in China. However, mercury pollution in the Songhua River in the 1960s that had adverse effects on the health of fishermen was a typical example. Industrial wastewater was discharged into the Songhua River in the beginning of the 1960s. As a result, the river became a typical example of a water body with methylmercury pollution. The mean mercury concentration found in the hair of some local fishermen was $13-58$ folds of the RfD value $(0.75 \mathrm{ppm})$ [11]. In addition, several cases of methylmercury poisoning were identified [12]. Since the elimination of major sources of mercury pollution in the 1980s in the Songhua River, the level of mercury in fishermen's hair have descended tremendously by $78.30 \%-82.57 \%$ from the mercury level in the 1970s. Nevertheless, the mercury concentrations found in the hair of the local residents are still notably higher than those of residents in other areas [13]. After more than 20 years of unremitting treatments, the Songhua River mercury pollution has finally been brought under contro1 [14]. 


\section{Arsenism}

Apart from the health risks of anthropogenic water pollution, biogeochemical diseases lead to another severe waterrelated problem in China, such as arsenism. Arsenicosis was first reported in the 1980s to affect population of large areas through drinking water in the Xinjiang Autonomy Region. This was followed by reports from the Inner Mongolia Autonomy Region, Shanxi Province and other districts. Between 2001 and 2005, 21,155 of 445,638 wells in 20,517 villages in 292 counties of 16 provinces in China, or 5\% of the total number of wells, were found to contain arsenic with levels higher than the national limit value $(50 \mu \mathrm{g} / \mathrm{L})$. It is estimated that 582,769 people were exposed to $>50 \mu \mathrm{g} / \mathrm{L}$ arsenic in drinking water [15]. Previous researchers found evidence of an association between exposure to arsenic via drinking water and skin lesions, peripheral vascular diseases, cancers and other adverse effects. Recent studies attempt to predict other adverse health effects resulting from arsenic exposure. An investigation in Inner Mongolia indicated that the mental health of subjects in the arsenic-affected village was worse than those in the arsenic-free village $(O R=2.5$, 95\% CI=1.1-6.0) [16]. Another investigation in Shanxi Province uncovered that exposure to arsenic in drinking water may affect children's intelligence and growth [17]. A crosssectional study in Inner Mongolia showed that chronic exposure to arsenic from drinking caused oxidative stress in humans [18]. Furthermore, a recent study demonstrated monotonic dose-response association between arsenic exposure from drinking water and elevated levels of systolic and diastolic blood pressure in a population of healthy women who are at the reproductive age [19]. In conclusion, the reduction of exposure to arsenic via drinking water still remains a challenge in China.

\section{Microcystins and Cancers}

Due to increasingly aggravated water pollution, the eutrophication of fresh water in China has become a serious problem. Sixty percent of natural freshwater lakes are undergoing eutrophication processes and blooms of cyanobacteria frequently occurr, posing potential threats to public health. As early as the 1970s, Su et al. carried out studies in 4 counties of the Jiangsu province with a high incidence of liver cancer. It was found that the liver cancer prevalence was associated with drinking water contamination [20]. Subsequent studies demonstrated that the high morbidity there due to liver cancer there was closely related to high concentrations of microcystins in drinking water [21]. Other studies also showed association between the incidence of colorectal cancer and drinking water, which may be related to microcystin contamination of drinking water [22].

\section{Organic Pollutants and Health}

A large amount of industrial waste water and domestic sewage is discharged into bodies of water with inadequate treatment, resulting in an abundant source of genotoxic pollutants in water, including many kinds of mutagenic and carcinogenic organics. A black list of 68 priority pollutants in China's water has been proposed. Among them, 58 toxic organic pollutants were involved, revealing the predomination of organic pollutants in water pollution in China [23]. A nationwide study on organic pollution of drinking water and liver cancer showed that liver cancer mortality was posi- tively correlated with the chemical oxygen demand (COD) in drinking water [24]. Results of a retrospective study in areas along the Second Songhua River demonstrated that carcinoma mortality among residents was related to the organic water pollution [25]. Concerns about potential adverse health effects associated with chronic exposure to chlorinated drinking water have been also raised. Chlorinated river and lake water was found to cause oxidative damage, DNA migration and cytotoxicity in vitro study [26, 27]. However, epidemiological studies on health effects of chlorination disinfection by-products in drinking water are still limited in China.

\section{Water Pollution Accidents}

Water pollution accidents are becoming more common in China, producing increasingly adverse impacts on public health. In 2006, the State Environment Protection Administration of China reported 161 environmental emergency accidents, among which 95 or $59 \%$ were water pollution accidents [3]. A prime incident was the Songhua River pollution accident in 2005. On November 13, 2005, a benzene and nitrobenzene plant in the Jilin Chemical Branch of China National Petroleum Corporation exploded. Approximately 100 tons of benzene, nitrobenzene and aniline were discharged into the Songhua River, forming a pollution belt of nearly $100 \mathrm{~km}$ downstream the Songhua River and flowing into the Heilongjiang River. The lives and production of more than 4 million residents along the riverbanks were impaired [5]. On May 29 $9^{\text {th }}, 2007$, a fetid bloom of algae in Taihu Lake caused the tap water supply to the city of Wuxi to be cut for days. This again aroused the concerns of the public and the government.

On account of the serious condition of water pollution in China and its threats to social development and public health, government agencies, research institutes and other organizations in China have conducted a great deal of researches supported by a great variety of funds, including the National Natural Science Foundation of China (NSFC), the National Basic Research Program of China (973 Program), Hi-Tech Research and Development Program of China (863 Program), Key Technologies R\&D Program, special fund of the State Environment Protection Administration, and so forth. Researches cover a large range of fields including the prevention and management of water pollution, health impact of water pollution, safety evaluation of drinking water and a warning system as well. In 2007, the Water Pollution Prevention and Control Law of People's Republic of China (revised draft) was unveiled and the new Standards for Drinking Water Quality came into effect, indicating that China is ready to make efforts to meet the growing demands of drinking water quality and safety.

\section{ACKNOWLEDGEMENTS}

The authors would like to thank Minyue (Mendy) Yang for her great help in English Editing. This work was supported by funding from the National Natural Science Foundation of China (NNSFC, grant No. 20577012).

\section{REFERENCES}

[1] Wang Y, Zhu K. Chinese water resources actuality and the strategies of its sustainable use. Journal of Lanzhou Jiaotong University 2005; 24(5): 78-80. (in Chinese). 
[2] Cao J. The situation of drinking water safety in China. Carcin, Teratogen Mut 2007; 19(3): 165-7. (in Chinese).

[3] State Environmental Protection Administration of China. Report on the State of the Environment in China 2006 2006; [cited 2006 June 04]; Available from: http: //www.zhb.gov.cn/plan/zkgb.

[4] State Environmental Protection Administration of China. Report on the State of the Environment in China 1996 1996; [cited 2002 Sep 15]; Available from: http: //www.zhb.gov.cn/plan/zkgb.

[5] Ministry of Water Resources, P.R. CHINA 2005 Water Resources Bulletin 2005; [cited 2007 January 17]; Available from: http: //www.hydroinfo.gov.cn/gb/szyzlnb/2005/2.htm.

[6] Lu Q, Li C, Li T. Suvey of pollution of ground water in our country. Chin J Ind Hyg Occup Dis 2006; 24(5): 317-20. (in Chinese).

[7] Wen D, Wu X, Zhang E, Lin L, Wu D. Issues and countermeasures on groundwater exploitation and utilization in China: 2006: The 34th Congress of International Association of Hydrogeologists; 2006 Sep; Beijing, China. (in Chinese).

[8] Ministry of Water Resources, P.R. CHINA 2006 Water Resources Bulletin 2006; [cited 2007 September 27]; Available from: http: //www.mwr.gov.cn/xygb/szygb/qgszygb/20070927150937e792cd.a spx.

[9] Zou H, Xu X, Zhang J, Zhu Z. The determination of strong mutagen MX [3-chloro-4-(dichloromethyl)-5-hydroxy-2(5H)furanone] in Drinking Water in China. Chemosphere 1995; 30(12): 2219-25. (in Chinese).

[10] Ministry of Health (MoH). Annual Health Statistics of China, 2005: Beijing. Ministry of Water Resources (MWR). Annual Report, 2005: Beijing. (in Chinese).

[11] Lin XW, Bao LP. A study of hazard of methylmercury pollution in No. 2 Songhua River to fishermen's health. Chin J Prev Med 1990; 24: 65-9. (in Chinese).

[12] Hou TN, Gu GZ, Zhao JX, Guo XF, Xu J, Bao LP. Clinical survey and analysis of fishermen's health affected by $\mathrm{MeHg}$ pollution in Songhua River. J Environ Health 1994; 11: 147-9. (in Chinese).

[13] Wu SA, Bo P, Li YH, Zhang GL, Qiu BY, Guan M. Study on the level of mercury in fishmen's hair since the elimination of major sources of mercury pollution in the Songhuajiang River. Chin J Environ Sci 1994; 15: 39-40. (in Chinese).

[14] Li J, Ye L, Gao T, Hu ML, Jin MH, Li J. Investigation on present environmental condition of Songhua river mercury pollution after comprehensive treatment. Chin J Public Health 2005, 21: 1494-5. (in Chinese).
[15] Yu GQ, Sun DJ, Zheng Y. Health effects of exposure to natural arsenic in groundwater and coal in China: an overview of occurrence. Environ Health Perspect 2007; 115(4): 636-42.

[16] Fujino Y, Guo XJ, Liu J. Mental health burden amongst inhabitants of an arsenic-affected area in Inner Mongolia, China. Soc Sci Med 2004; 59: 1969-73

[17] Wang SX, Wang ZH, Cheng XT, et al. Arsenic and fluoride exposure in drinking water: children's IQ and growth in Shanyin County, Shanxi Province, China. Environ Health Perspect 2007; 115: 643-7.

[18] Pi JB, Yamauchi H, Kumagai Y, et al. Evidence for induction of oxidative stress caused by chronic exposure of Chinese residents to arsenic contained in drinking water. Environ Health Perspect 2002; 110: 331-6.

[19] Kwok RK, Mendola P, Liu ZY, et al. Drinking water arsenic exposure and blood pressure in healthy women of reproductive age in Inner Mongolia, China. Toxicol Appl Pharm 2007; 222: 337-43.

[20] Su DL. Drinking water and liver cell cancer: an epidemiological approach to the etiology of this disease in China. Chin Med J 1979; 92: 748-56.

[21] SZ, Zhao N, Zi XL, et al. The relationship between cyanotoxin in pond-ditch water and primary liver cancer in China. Chin J Oncol 2001; 23: 96-9. (in Chinese)

[22] Zhou L, Yu H, Chen K. Relationship between microcystin and colorectal cancer. Biomed Environ Sci 2002; 15: 166-71.

[23] Zhou WM, Fu DQ, Sun ZG. Determination of black list of China's Priority Pollutants in water. Res Environ Sci 1991; 4: 9-12. (in Chinese).

[24] Wang Q, Chen CJ. The correlative study on the Chinese drinking water organic pollution and the mortality rate of liver cancer. J Hyg Res 1992; 21: 181-3. (in Chinese).

[25] Li YH, Xiang XK, Tang X, Zhu YL, Li DY. Retrospective study on correlation between water pollution of Second Songhua River and mortality of carcinoma in residents along river. J Environ Health 1998; 15: 176-8. (in Chinese).

[26] Yuan J, Wu XJ, Lu WQ, et al. Chlorinated river and lake water extract caused oxidative damage, DNA migration and cytotoxicity in human celss. Int J Hyg Environ Health 2005; 208: 481-8.

[27] Lu WQ, Chen D, Wu XJ, et al. DNA damage caused by extracts of chlorinated drinking water in human derived liver cells (HepG2). Toxicology 2004; 198: 351-7. 